\title{
Influence of nitrogen addition on oxyacetylene flame chemical vapor deposition of diamond as studied by solid state techniques and gas phase diagnostics
}

\author{
R. L. Stolk and M. M. J. W. van Herpen \\ Applied Physics, Research Institute for Materials, Toernooiveld 1, 6525 ED Nijmegen, The Netherlands \\ J. J. Schermer \\ Solid State Physics III, Research Institute for Materials, Toernooiveld 1, 6525 ED Nijmegen, \\ The Netherlands \\ J. J. ter Meulen ${ }^{a)}$ \\ Applied Physics, Research Institute for Materials, Toernooiveld 1, 6525 ED Nijmegen, The Netherlands
}

(Received 25 June 2002; accepted 10 December 2002)

\begin{abstract}
The effect of nitrogen addition on oxyacetylene flame deposition of diamond has been investigated. Two-dimensional laser-induced fluorescence measurements of $\mathrm{CN}$ radical distributions in the flame during deposition have been performed. These measurements show that nitrogen added to the source gases and nitrogen from the ambient air dominate the $\mathrm{CN}$ formation in the central and outer-flame area, respectively. Both sources of nitrogen have a significant influence in the area between the other two. Most of the observed film morphologies, which were studied by scanning electron microscopy, can be understood from the recently developed deterioration-gradient (DG) model for chemical vapor deposition of diamond, reported by J. J. Schermer et al. [J. Cryst. Growth 243, 302 (2002)]. It was found that the nitrogen range in which the $\alpha$-parameter, defined by C. Wild et al. [Diamond Relat. Mater. 2, 158 (1993)], changes from slightly below or equal to 1.5 to a value of 3 or more, is extremely narrow. This implies that under the present experimental conditions it is very hard or impossible to grow a layer with a central area consisting of $\langle 001\rangle$ oriented $\{001\}$ topped crystallites. Observed radial changes in the morphology of the sample grown without nitrogen addition were explained from radial changes in the gas phase composition, caused by interaction of the flame with nitrogen and, presumably, oxygen from the ambient air. The central growth rate as a function of the nitrogen flow shows an increase by more than a factor of 1.5 in going from 0 to $5 \mathrm{sccm}$ and stays more or less constant between 5 and $25 \mathrm{sccm}$. From Raman spectra of the central area it clearly followed that under the present conditions even the smallest added nitrogen addition resulted in a decrease of the film quality. This may be related to a possible stimulation of the growth of non-diamond carbon compounds by nitrogen. A correlation, the origin of which is not known, was found between the stepwise narrowing of a broad band in the Raman spectra, which was attributed to non-diamond carbon, and changes in the morphology of the diamond films. Combining the present data with findings from literature, support is generated for the idea that $\mathrm{CN}$ is important in causing the effects of nitrogen on diamond growth. (c) 2003 American Institute of Physics.
\end{abstract}

[DOI: $10.1063 / 1.1542691]$

\section{INTRODUCTION}

Chemical vapor deposition (CVD) techniques for the growth of diamond layers have opened a wide range of applications for this very promising material. Nitrogen addition during diamond CVD widens the possibilities, because it can favorably alter the properties of the deposited diamond. Under appropriate conditions nitrogen addition favors an $\langle 001\rangle$ texturing of the diamond layers, ${ }^{1-5}$ enabling the growth of smooth films with $\{001\}$ crystallite facets parallel to the substrate surface. Another effect of nitrogen addition is an enhancement of the growth rate. ${ }^{1,5,6-8}$ Despite considerable research effort the mechanisms through which nitrogen affects diamond growth are not known and due to the large differ-

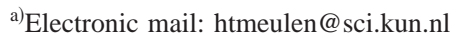

ences in growth conditions, these mechanisms may differ for the various CVD techniques. By use of techniques such as secondary ion mass spectrometry, ${ }^{9}$ photoluminescence (PL) ${ }^{10}$ cathodoluminescence $(\mathrm{CL}){ }^{5,11}$ and elastic recoil detection, ${ }^{12}$ it has been shown that nitrogen is incorporated into the diamond crystal lattice of layers that have been deposited with nitrogen addition. For its incorporation it is necessary that nitrogen is transferred from the gas phase to the growing diamond surface by one or more reactive nitrogencontaining species. A very useful deposition technique for obtaining insight into the mechanisms of nitrogen influence on diamond CVD is oxyacetylene flame deposition in open air. Nitrogen from the air enters the flame and interacts with it to form nitrogen-containing species. ${ }^{13}$ As a consequence, the gas phase from which diamond is grown is not homogeneous in radial direction. This is reflected in the radial inho- 
mogeneity of the deposited diamond layers. In the central area, no nitrogen or very little nitrogen is detected by means of CL. ${ }^{11,14,15}$ In an annulus of enhanced growth and roughness typical for flame-grown samples, ${ }^{13,16}$ which has a morphology different from that in the center, a relatively large amount of nitrogen is incorporated. ${ }^{11,14}$ The morphology of the central area changes if nitrogen is added to the flame and $\mathrm{CL}$ also shows nitrogen incorporation. ${ }^{5}$ It follows that the observed difference between the center and annulus in samples grown without nitrogen addition results from the presence of nitrogen and the annulus is a result of an interaction between the flame and nitrogen from the ambient air. This leads to the suggestion that nitrogen-containing species that are responsible for the observed effects of nitrogen on diamond CVD, should be present in the gas phase above the annulus. Since an annulus is mostly still observed if nitrogen is added to the flame, the radial concentration profile of the responsible nitrogen species should also have a radial concentration profile with maxima away from the center. Okkerse et al. ${ }^{17-19}$ performed two-dimensional numerical simulations of oxyacetylene flame deposition with the addition of nitrogen, and used the necessary presence of off-axis maxima in the concentration profile to select the nitrogencontaining species that may be of direct importance for the influence of nitrogen addition on diamond growth. They end up with $\mathrm{N}, \mathrm{NH}, \mathrm{NH}_{2}, \mathrm{NH}_{3}, \mathrm{CN}, \mathrm{HCN}$, and $\mathrm{NCO}$, excluding, e.g., NO, which shows a different concentration profile. From the list of possible candidates most information with respect to diamond growth is reported on $\mathrm{CN}^{14,15,17-24}$ and HCN. ${ }^{8,17-19,25,26}$

HCN has been measured by means of molecular beam mass spectrometry in a hot filament reactor and was found to be the dominant nitrogen-containing gas phase molecule..$^{25,26}$ With respect to this it should be stressed that it was not possible to measure nitrogen-containing radicals. In the case of oxyacetylene flame CVD, the simulations by Okkerse et al. ${ }^{17-19}$ and calculations by Atakan et al. ${ }^{8}$ show that the $\mathrm{HCN}$ radical is one of the dominant gas phase species when nitrogen is added.

For the $\mathrm{CN}$ radical more experimental data are available, which have been measured in various CVD reactors using a number of optical techniques. Optical emission spectroscopy has been used to detect $\mathrm{CN}$ during microwave $\mathrm{CVD}^{2,20,27}$ and in a dc-arc jet reactor. ${ }^{23}$ Conventional absorption, ${ }^{21,22}$ cavity ring down spectroscopy (CRDS), ${ }^{28}$ and two-dimensional laser-induced fluorescence (LIF) ${ }^{14,15}$ have been applied for measuring $\mathrm{CN}$ in oxyacetylene flame CVD. In the LIF measurements radial $\mathrm{CN}$ profiles showed off-axis maxima, which corresponds with the mentioned numerical simulations. ${ }^{17}$ It was found that the maxima in the radial LIF profiles were slightly further away from the center than the maxima of the radial growth rate profile. From a simple explanation it followed that the observed positional difference is to be expected for any (nitrogen-containing) species that causes an enhanced growth rate, ${ }^{15}$ and that it therefore supports a possible role of the $\mathrm{CN}$ radical in the growth mechanism. Butler ${ }^{29}$ has proposed a surface mechanism, which explains, among other things, the increased twin density on diamond $\{111\}$ faces, which occurs upon nitrogen addition. In this mechanism nitrogen is incorporated into the diamond via attachment of the $\mathrm{CN}$ radical to a reactive surface site.

Only a small number of articles deals with controlled nitrogen addition during oxyacetylene flame deposition. Atakan et al. ${ }^{8}$ have investigated the effect of the addition of four different nitrogen compounds. For the addition of molecular nitrogen they found that the diamond growth rate as a function of the added amount of nitrogen first showed an increase and then reached a plateau, and that the diamond quality decreased upon nitrogen addition. Schermer and De Theije ${ }^{5}$ have studied the influence of nitrogen addition and found a maximum in the central area growth rate as a function of the nitrogen addition. For a specific range of nitrogen additions they observed that the central area of their films was $\langle 001\rangle$ textured with $\{001\}$ topped crystallites. Finally there are the numerical simulations of Okkerse et al. ${ }^{17-19}$ mentioned above.

The experiments described in this article were performed with a set-up very similar to that used by Schermer and De Theije ${ }^{5}$ under partly different conditions. Diamond layers were grown with a range of nitrogen additions and were characterized by a number of techniques. Scanning electron microscopy (SEM) was used to study the morphology, optical microscopy to determine the growth rate and Raman spectroscopy to assess the quality and composition of the films. During deposition, LIF was employed to measure twodimensional $\mathrm{CN}$ distributions in a way described in previous work. ${ }^{14,15,24}$ This laser technique provides a sensitive, highly specific, and non-intrusive way to measure species distributions in a variety of environments including flames. ${ }^{30,31}$ When saturation is avoided, the fluorescence signal is linearly proportional to the concentration of the species under examination. At atmospheric pressure, however, the proportionality constant, which is related to collisional quenching, is not known. Therefore no absolute concentrations follow from the measurements. In this article radial profiles of the CN LIF signal at $100 \mu \mathrm{m}$ above the substrate are used for further analysis and, as will be discussed in Sec. III A, can be regarded as semi-quantitative, at least within an area with a radius of $1.5 \mathrm{~mm}$.

\section{EXPERIMENT}

The setup and method used for oxyacetylene flame deposition of diamond, have been described extensively by Schermer et al..$^{32}$ Adaptations necessary to enable controlled nitrogen addition can be found in articles by Schermer and De Theije ${ }^{5}$ and Stolk et al. ${ }^{15}$ For the reader's convenience a short overview of the main aspects of the set-up and the experimental parameters will be given. The flame was fed with highly pure gases (Indugas). A mixture of acetylene (99.6\%), oxygen $(99.995 \%)$, and if added, nitrogen is burnt with an unmodified commercial welding torch with an orifice of $1.3 \mathrm{~mm}$ in diameter. Mass flow controllers (MFC) are used to regulate the gas flows. The oxygen flow is set at a constant value of 2.5 standard liters per minute (SLM) and the acetylene flow is tuned to give an acetylene supersaturation $\left(S_{\mathrm{ac}}\right)$ of $4 \% . S_{\mathrm{ac}}$ is defined as the percentage of excess acetylene fed to the burner compared to the amount needed 
TABLE I. Overview of the nitrogen flows added to the flame and the corresponding distances $d$ between the flame front and the substrate.

\begin{tabular}{cc}
\hline \hline $\begin{array}{c}\text { Nitrogen flow } \\
(\mathrm{sccm})\end{array}$ & $\begin{array}{c}d \\
(\mathrm{~mm})\end{array}$ \\
\hline 0 & 2.1 \\
5 & 2.0 \\
10 & 2.3 \\
15 & 2.1 \\
25 & 2.2 \\
40 & 2.0 \\
60 & 2.1 \\
80 & 1.8 \\
100 & 1.8 \\
\hline \hline
\end{tabular}

to obtain a neutral flame with the same oxygen flow, a neutral flame being one that is neither acetylene nor oxygen rich. ${ }^{32}$ Nitrogen is added via a line connected to the oxygen line, with a flow ranging between 0 and 100 standard cubic centimeters per minute $(\mathrm{sccm})$, which corresponds to nitrogen concentrations between 0 and 18 ppt (parts per thousand). The total gas flow is about 5.5 SLM. For an optimal use of the nitrogen MFC, nitrogen flows of $25 \mathrm{sccm}$ and lower are added from a nitrogen/oxygen mixture (29.5/70.5), whereas larger nitrogen flows are added from a bottle with pure nitrogen (99.999\%). The oxygen flow is corrected for the extra oxygen that is added when the mixture is used.

Diamond deposition takes place on a $12 \times 12 \times 0.5 \mathrm{~mm}^{3}$ molybdenum square with a controlled surface temperature of $1025^{\circ} \mathrm{C} \pm 15^{\circ} \mathrm{C}$. The substrate is pretreated by scratching it with $\mu \mathrm{m}$-sized diamond powder in a standard way. ${ }^{5,15}$ The distance between the flame front and the substrate, determined by using a CCD camera, ${ }^{33}$ lies in the range between 1.8 and $2.3 \mathrm{~mm}$ and is specified for each sample in Table I. All growth runs lasted for $1 \mathrm{~h}$, except for the one performed with an added nitrogen flow of $5 \mathrm{sccm}$. This run was stopped after 55 min because of problems with the cooling of the substrate.

The two-dimensional LIF measurements are performed in a way similar to the one used by Klein-Douwel et al. ${ }^{14}$ and have been described in previous work. ${ }^{15}$ The $\mathrm{CN}$ radical is detected by using the rotational bandhead at $359.1 \mathrm{~nm}$ of the $B^{2} \Sigma^{+}\left(v^{\prime}=1\right) \leftarrow X^{2} \Sigma^{+}\left(v^{\prime \prime}=0\right)$ transition for excitation and collecting the fluorescence of the $\left(v^{\prime \prime}=1, v^{\prime}=1\right)$ transition. Tunable laser light suitable for inducing excitation is generated by KDP frequency doubling of the output of a Nd:YAG-dye laser combination (Quantel YG $781 \mathrm{C} 10$ and Quantel TDL 50, respectively) running on Pyridine 1. The resulting laser light has a bandwidth of $0.25 \mathrm{~cm}^{-1}$ and is emitted in $5 \mathrm{~ns}$ pulses at a repetition rate of $10 \mathrm{~Hz}$. To enable $\mathrm{CN}$ detection in a two-dimensional plane, a system of cylinder lenses is used to shape the laser beam into a vertical sheet, which is guided through the center of the flame. At the position of the flame the sheet has a laser power of about 50 $\mu \mathrm{J} /$ pulse. Detection of the fluorescence is done by means of an image-intensified Peltier-cooled CCD camera (La Vision Flame Star II), which is positioned in a direction perpendicular to that of the laser beam. It is equipped with four reflection filters (Laser Optik) with a bandwidth of about $13 \mathrm{~nm}$, to

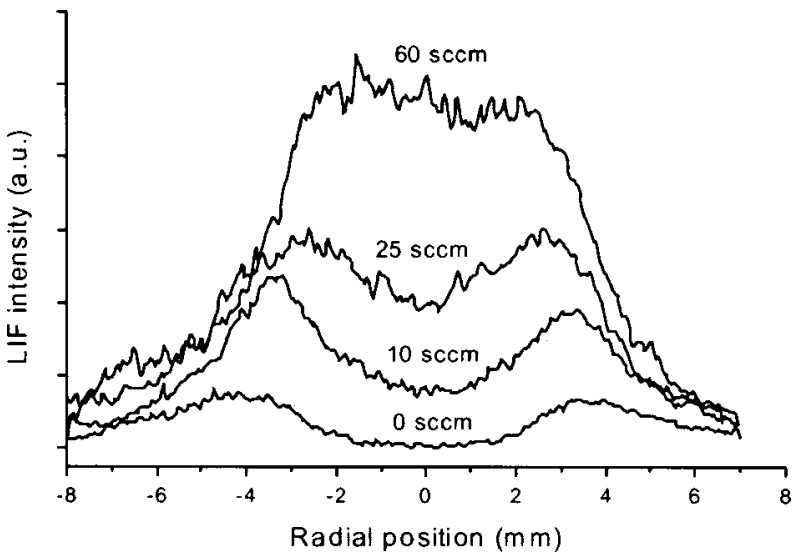

FIG. 1. Radial profiles of the CN LIF signal for the indicated nitrogen additions; the profiles represent the CN LIF intensity of an $80 \mu \mathrm{m}$ high strip centered at $100 \mu \mathrm{m}$ above the deposition substrate.

select the fluorescence from the $\left(v^{\prime \prime}=1, v^{\prime}=1\right)$ transition. The camera is triggered by the $Q$ switch of the laser and opens after a delay for a time window of $20 \mathrm{~ns}$, thus reducing the natural flame emission by a factor of $5 \times 10^{6}$. Care is taken to avoid saturation of the $\mathrm{CN}$ excitation. ${ }^{34}$ The measured LIF distributions are corrected for background signal by subtraction of an off-resonant LIF image from a resonant one measured at $359.1 \mathrm{~nm}$. After this the resulting signal is corrected for the inhomogeneous vertical distribution of the laser power in a method similar to that described in Ref. 14. All resonant and off-resonant images are averages of ten images, each of which is composed of the summed signal of 100 laser shots. The spatial resolution is $40 \mu \mathrm{m}$.

SEM images to study the morphology of the diamond films are recorded on a field emission gun scanning electron microscope (JEOL JSM $6330 \mathrm{~F}$ ). The central growth rate of the diamond layers is determined by measuring the thickness of the diamond films by means of an optical microscope, ${ }^{32}$ the accuracy of the measured layer thickness is about $\pm 5 \mu \mathrm{m}$. Raman spectra (Dilor $X Y$ multichannel spectrometer), from which information about the layer quality and composition can be extracted, are recorded at room temperature, using the $514 \mathrm{~nm}$ line of an $\mathrm{Ar}^{+}$laser for excitation. The signal is detected with a photodiode array. Because the spot size is about $1 \mathrm{~mm}^{2}$ the recorded Raman spectra do not result from one single crystallite, but are integrated over a large number of crystallites and grain boundary material. Raman spectroscopy is only used for studying the central area of the samples.

\section{RESULTS}

\section{A. LIF measurements}

Figure 1 shows horizontal LIF intensity profiles that have been obtained from the measured two-dimensional $\mathrm{CN}$ LIF distributions. The profiles are the average signal of an 80 $\mu \mathrm{m}$ high strip centered at $100 \mu \mathrm{m}$ above the substrate. To account for run-to-run differences in, e.g., exact alignment, they were scaled as described in Ref. 15. In other work ${ }^{28}$ it was found that the shape of LIF profiles taken at $720 \mu \mathrm{m}$ above the substrate is similar to that of absolute concentra- 
tion profiles, measured with cavity ringdown spectroscopy (CRDS) at the same height in a nearly identical system and under very similar conditions. Assuming that such a similarity also exists at a smaller height above the substrate, this means that the shape of the observed LIF profiles reflects the actual radial distributions of the $\mathrm{CN}$ radical. Besides, it also shows that a radial variation of collisional quenching is not dominant in determining the shape of the LIF profile. In Fig. 1 it can be seen that for the measurement without nitrogen addition hardly any signal is detected in the center, whereas there clearly is LIF intensity at some distance outside the center. This observation is in correspondence with work of Klein-Douwel et al. ${ }^{14}$ The $\mathrm{CN}$ responsible for the maximum outside the center is formed in an interaction between the flame and nitrogen from the ambient air. ${ }^{13}$ The observation that the LIF maximum on the left-hand side, which is the side from which the laser beam enters the flame, is stronger than the one on the right-hand side may be explained by the attenuation of the laser beam by the flame. Because of the absence of saturation effects the LIF signal is linearly proportional to the exciting laser power, which means that a lower power results in a lower signal. Both the maximum and the central LIF signal increase upon nitrogen addition, but the height of the maximum with respect to the central signal decreases, which results in a relatively flat LIF profile for a nitrogen addition of $60 \mathrm{sccm}$. The LIF profiles measured at larger nitrogen flows, which are not displayed, look similar to the $60 \mathrm{sccm}$ profile.

From the LIF profiles in Fig. 1, it follows that in radial direction three areas can be identified, in which the LIF signal responds differently to the added nitrogen. Within a central area with a radius of about $2 \mathrm{~mm}$ around the flame axis the nitrogen signal is (almost) fully determined by the added nitrogen. This follows from the fact that without addition there is no signal and with addition there is. Further outside lies the area where the LIF maximum is situated. In this area both the added nitrogen and nitrogen from the ambient have an influence on the CN signal. This conclusion is based upon the observations that there is already signal when no nitrogen is added, and that this signal increases when nitrogen is added. Outside this area nitrogen from the ambient is expected to be the dominant nitrogen source for $\mathrm{CN}$ production, although even in this area some increase of the LIF signal occurs upon nitrogen addition (see Fig. 1). Taken together, it can be said that the influence of the added nitrogen decreases with increasing radial distance from the center. The opposite is true for nitrogen from the ambient. The division of the gas phase closely above the deposition substrate into three areas where the two nitrogen sources have a different relative importance for the $\mathrm{CN}$ production, is in agreement with earlier findings. ${ }^{5,15,24}$ Numerical simulations by Okkerse et al. ${ }^{17-19}$ on nitrogen addition during flame CVD of diamond support a dominant role for added nitrogen in the central area. They show that for values of $d$ up to at least 2.6 $\mathrm{mm}$, nitrogen from the ambient does not enter the central region. Furthermore, it follows from the simulations that the amount of nitrogen-containing species that diffuse from the outside of the flame to the center is insignificant when compared to the amounts generated from added nitrogen.

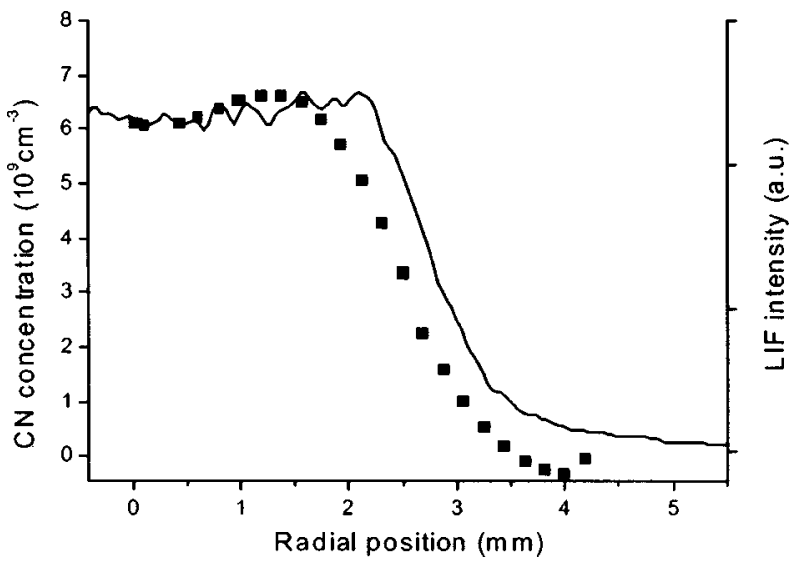

FIG. 2. CN LIF profile (solid line) obtained during the experiment with 60 sccm of nitrogen addition, representing the signal of an $80 \mu \mathrm{m}$ high strip centered at $740 \mu \mathrm{m}$ above the substrate, together with a CRDS profile (solid circles) measured under very similar experimental conditions with a nitrogen addition of $50 \mathrm{sccm}$ and at a height of $730 \mu \mathrm{m}$ above the substrate.

In Fig. 2, a LIF profile measured with a nitrogen addition of $60 \mathrm{sccm}$ is displayed together with the absolute $\mathrm{CN}$ density profile from CRDS measurements obtained for a nitrogen flow of $50 \mathrm{sccm} .{ }^{28}$ The LIF profile is the average signal of an $80 \mu \mathrm{m}$ high vertical strip, centered at $740 \mu \mathrm{m}$, the CRDS profile was measured at $730 \mu \mathrm{m}$ above the substrate. It can be observed that both profiles are flat within a radial position of $1.5 \mathrm{~mm}$. Because the LIF intensity is proportional to the product of $\mathrm{CN}$ concentration and detection efficiency (including quenching) it follows, that the detection efficiency in the area within a radius of $1.5 \mathrm{~mm}$ is constant. A constant detection efficiency implies that the collisional quenching does not change radially in the mentioned spatial range. Additionally, the flat concentration profile indicates a constant temperature in this area as well. It seems safe to assume that the radial constancy of temperature and quenching is also met closely above the substrate. With respect to the temperature profile this is supported by the results of numerical simulations, ${ }^{17,18,35}$ which close to the substrate show that the radial temperature profile is practically flat. A constant quenching in the central area should also hold for the other nitrogen additions, because the addition of nitrogen does not significantly influence the combustion chemistry of nonnitrogen species in the flame. ${ }^{18,19}$ Besides, a linear relation between the central CN LIF intensity and the added nitrogen flow reported in Ref. 15 for the current range of nitrogen flows, leads to the conclusion that nitrogen itself does not influence the LIF detection efficiency. From the above it follows that the LIF measurements can be looked upon as semiquantitative.

The observation of a radial maximum in the CN LIF signal for nitrogen additions between 0 and $25 \mathrm{sccm}$ in Fig. 1 implies that the signal must be the result of at least two effects. Important effects in this respect are the different local flame composition and temperature at different positions in the flame, and the way in which nitrogen is introduced into the flame. Different local conditions result in a different nitrogen chemistry and, thereby, influence the formation/ destruction of nitrogen-containing species, including $\mathrm{CN}$. 

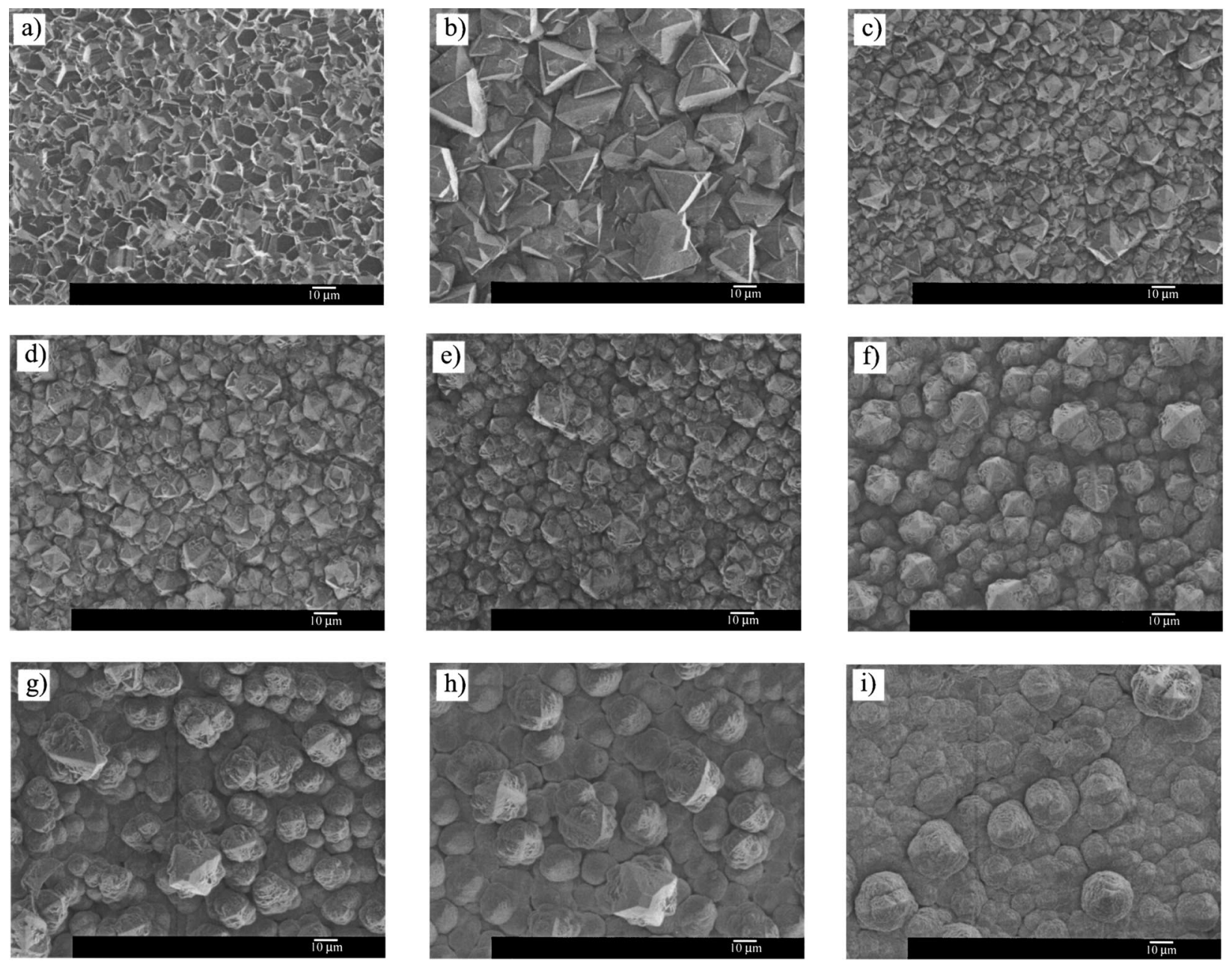

FIG. 3. SEM images of the morphology in the central area of the diamond films grown with nitrogen additions of: (a) $0 \mathrm{sccm}$, (b) $5 \mathrm{sccm}$, (c) $10 \mathrm{sccm}$, (d) $15 \mathrm{sccm}$, (e) $25 \mathrm{sccm}$, (f) $40 \mathrm{sccm}$, (g) $60 \mathrm{sccm}$, (h) $80 \mathrm{sccm}$, and (i) $100 \mathrm{sccm}$; the scale is indicated in the figures.

The way in which nitrogen enters the flame, whether it is via entrainment or diffusion from the ambient, or via addition to the source gases, determines the local conditions it experiences and in this way affects its conversion. Nitrogen that is added to the source gases, e.g., passes the primary flame front and meets completely different local conditions than ambient nitrogen that diffuses into the flame at some position. The interplay of the two mentioned effects leads to the evolution of the measured CN LIF signals as observed in Fig. 1, the changing ratio between added nitrogen and nitrogen from the ambient being an important parameter.

\section{B. Morphology}

Figure 3 shows the central area morphology of the grown samples. At a 0 sccm nitrogen addition [Fig. 3(a)] the central area of the layer shows a morphology, which is typical for flame grown samples: a closed layer formed by randomly oriented crystallites, which show $\{111\}$, as well as $\{001\}$ facets. At an addition of $5 \mathrm{sccm}$ [Fig. 3(b)] a completely different morphology is observed. The dominantly occurring crystallites have much larger linear dimensions than the ones in the $0 \mathrm{sccm}$ sample. The sample shows a high density of $\{111\}$ facets aligned more or less parallel to the substrate. Twin formation can be observed on most of these
$\{111\}$ top facets. As compared to the sample grown without nitrogen addition, the $5 \mathrm{sccm}$ sample has a significantly larger roughness.

For nitrogen additions starting at $10 \mathrm{sccm}$ [Fig. 3(c)], the crystallites are oriented with their $\langle 001\rangle$ crystallographic direction parallel to the surface, indicating $\langle 001\rangle$ fiber texture, and are bound by $\{111\}$ side faces. Virtually no $\{001\}$ top facets are observed, meaning that they have grown out of the crystallites by a high growth rate in the $\langle 001\rangle$ direction. At nitrogen flows of $10 \mathrm{sccm}$ and larger, the samples show groups of larger and of smaller crystallites, which evolve similarly with the added nitrogen flow, but at a different pace. The crystallites in both groups increase in size with an increasing nitrogen addition, while the number of larger crystallites decreases. From Figs. 3(c) to 3(i) $(10-100 \mathrm{sccm})$ the $\{111\}$ facets show increased twinning or other types of secondary nucleation ranging from almost clean facets for a nitrogen flow of $10 \mathrm{sccm}$ to practically completely deteriorated facets at $100 \mathrm{sccm}$. For the 10 and $15 \mathrm{sccm}$ sample a closed layer is seen. Starting at $25 \mathrm{sccm}$ the layer breaks up and the smaller crystallites become clearly more deteriorated than the larger ones. Close inspection of Fig. 3 reveals that the smaller crystallites are almost fully deteriorated for nitrogen flows of $40 \mathrm{sccm}$ and higher, whereas for the larger 

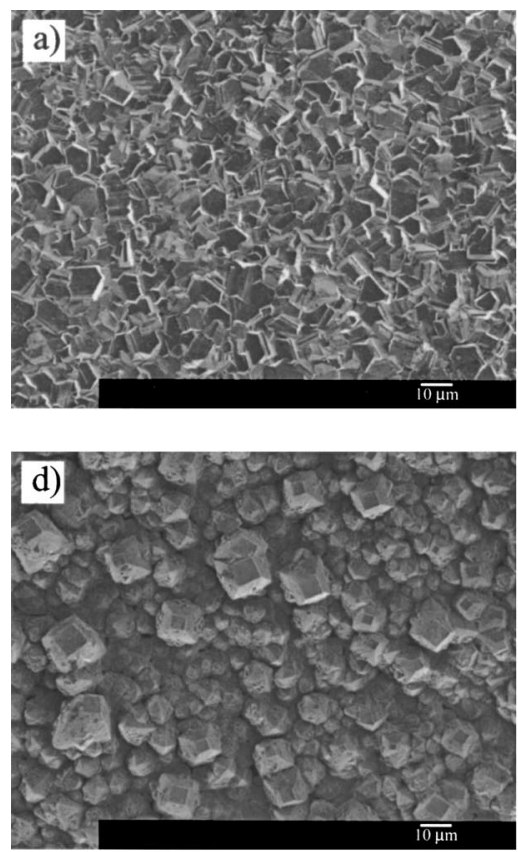
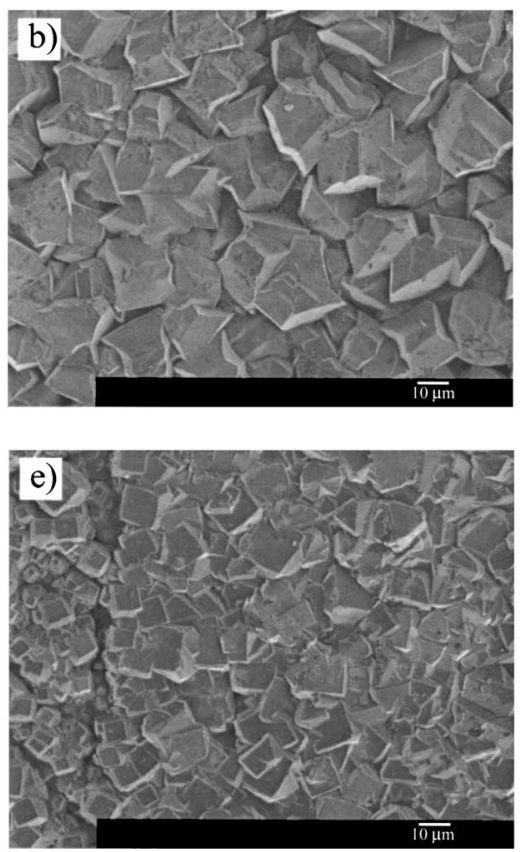
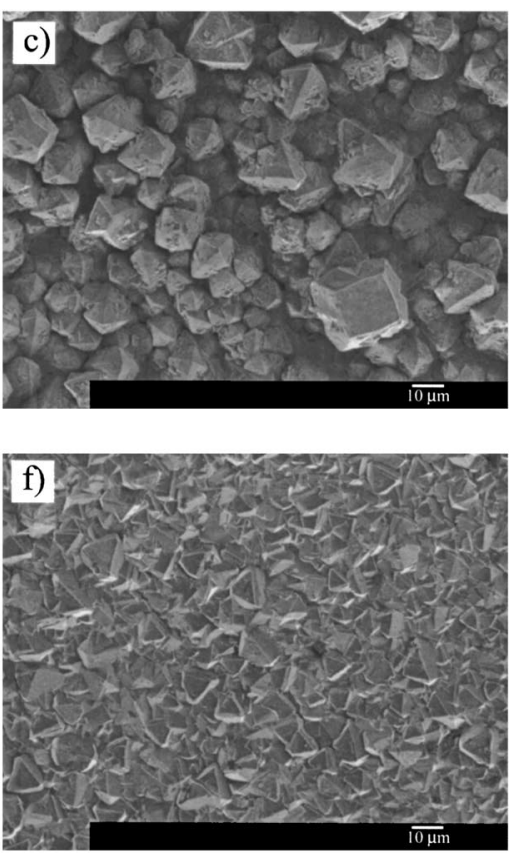

FIG. 4. SEM images of the morphology of the sample grown without nitrogen addition at different radial distances from the center: (a) 0 mm, (b) 2.4 mm, (c) $3.2 \mathrm{~mm}$, (d) $3.5 \mathrm{~mm}$, (e) $3.7 \mathrm{~mm}$, and (f) $4.1 \mathrm{~mm}$; the images are on the same scale as those in Fig. 3.

crystallites this is only the case for the $100 \mathrm{sccm}$ sample, for which only very few large crystallites are left.

In Figs. 4(a)-4(f) SEM images of the $0 \mathrm{sccm}$ sample taken at different radial positions and starting from the center are displayed, which reveal the large morphological diversity found for this sample. Figure 4(a) shows the morphology in the center of the sample, which can also be observed in Fig. 3(a). At a distance of $2.4 \mathrm{~mm}$ away from the center [Fig. 4(b)] the crystallite size has greatly increased, and the morphology shows some resemblance to that of the central area of the $5 \mathrm{sccm}$ sample [Fig. 3(b)]. The major difference is, that for the $5 \mathrm{sccm}$ sample the $\{111\}$ triangular shape is the dominant crystallite shape, whereas twin formation has undone this dominance in the morphology displayed in Fig. 4(b). Figure 4(c), an image taken at $3.2 \mathrm{~mm}$ outside the center, shows a variety of morphologies. All through the image, $\langle 001\rangle$ oriented crystallites are present with a morphology that

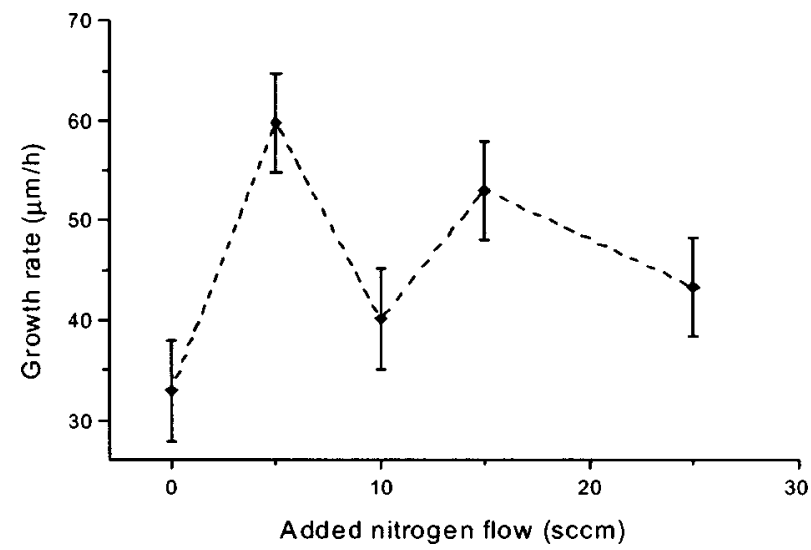

FIG. 5. Growth rate of the central area of the diamond layers; the inaccuracy shown by the error bars is about $5 \mu \mathrm{m}$; the dashed line is drawn to guide the eye. becomes more open when going from the left- to the righthand side of the figure, which is the direction away from the center. Both larger and smaller crystallites with the $\langle 001\rangle$ orientation are met. From these observations the morphology looks like that in the central area of the samples grown with $10 \mathrm{sccm}$ of nitrogen and more. Based on the extent of secondary nucleation on the $\{111\}$ side facets the morphology comes closest to the central area morphologies of the 25 and $40 \mathrm{sccm}$ samples. Besides the $\langle 001\rangle$ oriented crystallites without $\{001\}$ top facets, $\{001\}$ topped specimina are also found, as well as an occasional $\{111\}$ topped crystallite. More $\{001\}$ topped crystallites are observed in Fig. 4(d), which shows the morphology at a radial position of $3.5 \mathrm{~mm}$. Still, there are non-topped $\langle 001\rangle$ oriented crystallites and the morphology can be placed somewhere between the central area morphologies of the 40 and $60 \mathrm{sccm}$ samples [Figs. 3(f) and $3(\mathrm{~g})$, respectively], the crystallite size in Fig. 4(d) being smaller. On the left-hand side of Fig. 4(e), an image taken at $3.7 \mathrm{~mm}$ from the central axis, the density of $\{001\}$ topped crystallites has greatly increased. Finally, this gives rise to a beautiful morphological and structural phenomenon: a $\langle 001\rangle$ textured ring with a width of only some tens of $\mu \mathrm{m}$. Outside this ring, a closed layer with randomly oriented crystallites is found, as can be seen for a distance of $4.1 \mathrm{~mm}$ from the center in Fig. 4(f). Further outside, the morphology is the same, with crystallite dimensions that decrease with the radial distance. In all images where $\{001\}$ topped crystallites are found, it can be seen that these facets are not equally sized.

\section{Central area growth rate}

In Fig. 5, the average growth rate of the homogeneous central area is plotted for nitrogen flows up to $25 \mathrm{sccm}$. For all samples the growth rate of the highest layer of crystallites 

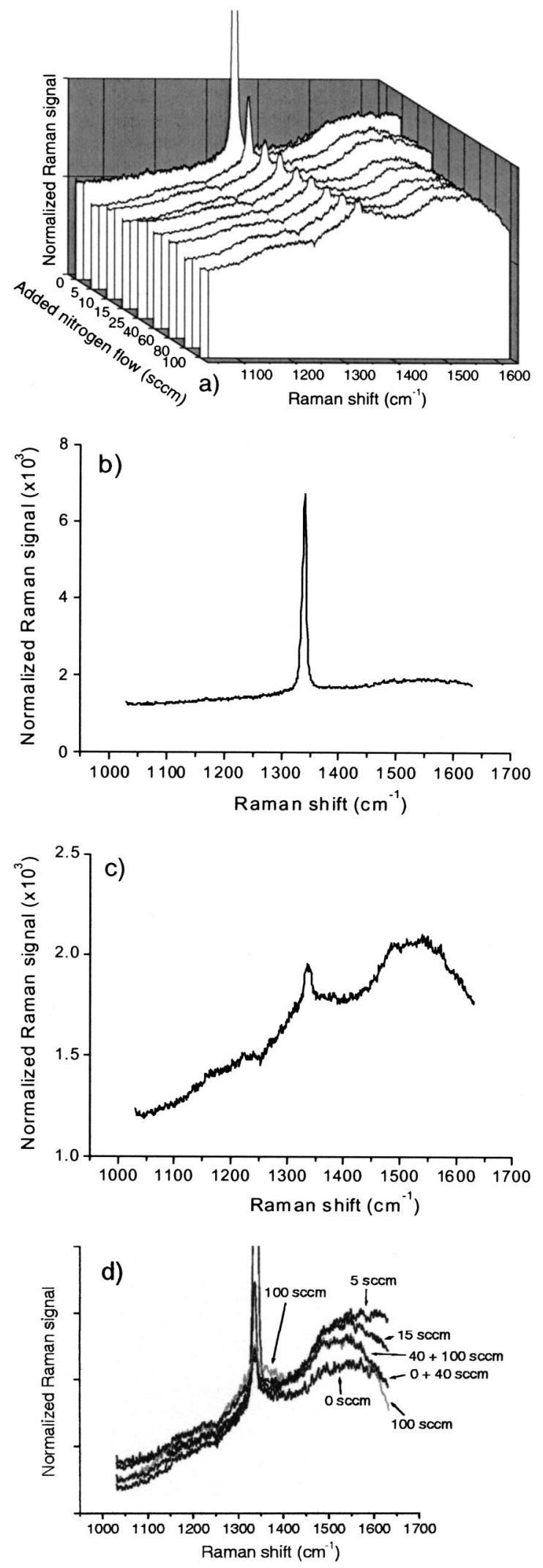

FIG. 6. (a) 3D plot showing the Raman spectra obtained from the central area of the diamond layers grown with the indicated nitrogen flows; the integrated area of the spectra is normalized to unity; due to its large relative strength the diamond peak of the $0 \mathrm{sccm}$ sample is off scale; (b) and (c) normalized Raman spectra of the central area of the samples grown with 0 and $40 \mathrm{sccm}$, respectively; note the different vertical scales used for these graphs; (d) overlay of the Raman spectra of the samples grown with the indicated nitrogen flows; for clarity, the spectrum of the sample grown with a nitrogen flow of $100 \mathrm{sccm}$ is shown in gray; same vertical scale as (c). is given. A nitrogen flow of $5 \mathrm{sccm}$ results in an increase of the growth rate with a factor of more than 1.5 , corresponding with the frequently reported nitrogen-induced growth rate enhancement. ${ }^{1,5-8}$ This increase in growth rate is clearly lower than that observed by Schermer and de Theije ${ }^{5}$ for their experiments with a similar set-up. The difference between our results and theirs must result from the different values for $d$ that have been used: our average value of 2.0 $\mathrm{mm}$ as compared to $1.2 \mathrm{~mm}$. From this it follows that the effect of nitrogen addition on the growth rate decreases when $d$ becomes larger. In Fig. 5 it can be noticed that for all nitrogen additions the growth rate is larger than that of the 0 sccm sample. At a nitrogen flow of $10 \mathrm{sccm}$ there is a dip in the graph. This may be explained by the fact that the value of $\mathrm{d}$ for the $10 \mathrm{sccm}$ sample was larger than for the surrounding 5 and $15 \mathrm{sccm}$ samples ( $2.3 \mathrm{~mm}$ as compared to 2.0 and 2.1 $\mathrm{mm}$, respectively), which is expected to result in a lower growth rate. ${ }^{32}$ In fact, the course of the growth rate as a function of the added nitrogen flow as shown in Fig. 5, except for the difference between the growth rates at 0 and 5 sccm, can (in part) be ascribed to the differences in $d$ values at which the samples were grown, if it is assumed that a larger $d$ leads to a lower growth rate and a smaller $d$ results in a higher-rate. Comparing the $d$ values for the samples between 0 and $25 \mathrm{sccm}$, which can be found in Table I, to their average value of $2.1 \mathrm{~mm}$ then shows that if $d$ had been equal for all samples, the growth rate for the $5 \mathrm{sccm}$ sample would have been relatively lower, whereas the rates for the 10 and $25 \mathrm{sccm}$ samples would have been higher, and the rates of the 0 and $15 \mathrm{sccm}$ samples would be equal to the current ones. It follows that accounting for the differences in $d$ reduces the fluctuations that are visible in Fig. 5. Conclusively, it can be said that the samples grown with nitrogen additions between 5 and $25 \mathrm{sccm}$ all have a larger central area growth rate then the $0 \mathrm{sccm}$ sample, and that the central area growth rate does not show a pronounced maximum as observed for the smaller $d$ value used in Ref. 5. For nitrogen addition during oxyacetylene flame CVD of diamond, Atakan et $a l .{ }^{8}$ report a relation between the growth rate and the added amount of nitrogen that resembles our results.

\section{Raman spectroscopy}

Figure 6(a) displays the Raman spectra of the central area of the samples. In Fig. 6(b) the spectrum of the $0 \mathrm{sccm}$ sample is displayed, which shows a very strong diamond Raman line and the lowest relative background signal of all samples. From the high diamond to non-diamond ratio it follows that the sample has a good quality. ${ }^{32}$ Because the present measurements are integrated over a large number of crystallites and grain boundaries, the ratio tells more about the quality of the sample as a whole than about the quality of the diamond crystallites. ${ }^{32}$ The grain boundaries contain much $s p^{2}$ carbon, which increases the background and therefore results in a diamond to non-diamond ratio that suggests a diamond quality worse than the actual one.

The spectrum of the $40 \mathrm{sccm}$ sample in Fig. 6(c) shows that this sample has a much lower quality than the $0 \mathrm{sccm}$ sample [note the different vertical scales of Figs. 6(b) and 
6(c)]. Because this spectrum contains all features that are observable in the series of spectra, it is a good starting point for analysis. With respect to its features it closely resembles a spectrum in a publication of Bachmann and Wiechert, ${ }^{36}$ supporting these authors' statement that spectra of flame deposited material can usually be synthesized from a number of basic features. The feature that is most easily recognized in all of our spectra is the diamond Raman peak, which indicates the presence of diamond in all films. Underneath the diamond peak there is a band that can be assigned to the $\mathrm{D}$ band of graphitic carbon, ${ }^{36,37}$ which is located at $1357 \mathrm{~cm}^{-1} .37$ The term graphitic denotes $s p^{2}$ hybridized carbon. ${ }^{37}$ As follows from the overlay of the spectra in Fig. 6(d) this band becomes stronger with the added nitrogen flow. On the low wave number side of the diamond peak, a very weak broad-band centered at about $1150 \mathrm{~cm}^{-1}$ can be observed, which can be attributed to nanocrystalline diamond. ${ }^{36,38}$ The band is strongest for the 80 and $100 \mathrm{sccm}$ samples, which may be caused by the very strong secondary nucleation on the crystallites of these samples. On the high wave number side, a stronger broad-band is visible for all samples, which can result from the graphitic $\mathrm{G} \mathrm{peak}^{36,37}$ at $1580 \mathrm{~cm}^{-1}, 37$ a tetrahedrally bonded diamond precursor ${ }^{38}$ and/or diamond-like carbon, ${ }^{37,39,40}$ which contains both $s p^{2}$ and $s p^{3}$ hybridized carbon and hydrogen. ${ }^{41}$ In Fig. 6(d) it can be seen that the broad-band starts at the same position for all nitrogen flows. At $5 \mathrm{sccm}$ it is broadest and has its highest relative strength. With increasing nitrogen flow the relative strength of the band decreases and it becomes stepwise narrower at nitrogen flows of 10,25 , and $60 \mathrm{sccm}$. Because the peak of nanocrystalline diamond and that of the tetrahedrally bonded diamond precursor usually appear simultaneously in spectra, ${ }^{36}$ the appearance of the former supports the expected presence of the latter. Likewise, the observation of the graphitic D band makes it probable that the $\mathrm{G}$ band is also in the spectrum. In this respect it should be noted that the intensity on the right-hand side of the high wave number broadband, where the $\mathrm{G}$ band is expected, decreases with an increasing nitrogen flow. In other words: with increasing nitrogen addition the relative intensity of the $\mathrm{D}$ band increases, whereas the signal at the position at which the $\mathrm{G}$ band is expected, weakens. In diamond-like carbon films the D band appears in spectra of films that are dominated by $s p^{2}$ bonding and denotes the presence of ordered clusters of $s p^{2}$ sites. ${ }^{42,43}$ Combining this with the observed relation between the relative intensity of the $\mathrm{D}$ band and the nitrogen addition, it follows that this relation indicates that nitrogen addition stimulates the formation of $s p^{2}$ carbon. From the ratio of the diamond peak and the presumed graphitic $\mathrm{G}$ band it can be said that graphitic $s p^{2}$ carbon is present in relatively small amounts, knowing that the Raman cross section of graphite is more than 50 times that of diamond. ${ }^{37}$

In all Raman spectra an upward slope is visible, which is approximately equally steep for all samples, except for the 0 sccm one, for which it is flatter. This slope is ascribed to background luminescence, ${ }^{36}$ which may come from $s p^{2}$ carbon $^{44,45}$ and impurities such as nitrogen. ${ }^{11,46}$ For the present samples $s p^{2}$ carbon most probably dominates the

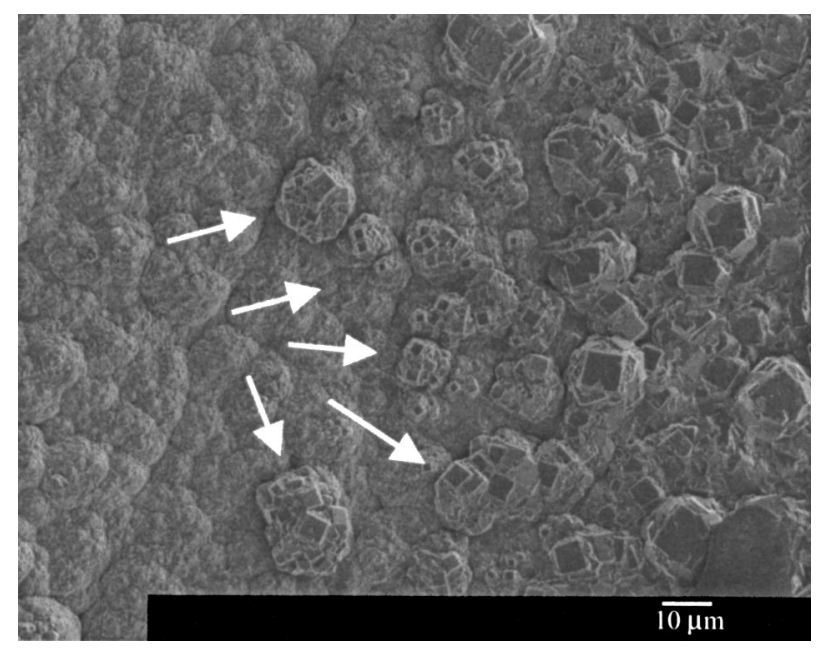

FIG. 7. SEM image showing some diamond hemispheres covered with $\{001\}$ facets (indicated by the arrows), present on the sample grown with $100 \mathrm{sccm}$ nitrogen.

background luminescence, since the luminescence does not show any correlation with the added nitrogen flow, as may be expected in the case of nitrogen-related luminescence.

When the Raman spectra of the 0 and $5 \mathrm{sccm}$ samples are compared, some things can be noticed. At $5 \mathrm{sccm}$ the relative intensity of the diamond peak is much lower, whereas that of the broad-band on the high wave number side is much higher, and the slope of the background signal is steeper. These observations point at an increase of the $s p^{2}$ carbon fraction and possibly of the diamond-like carbon fraction, upon the addition of nitrogen. This strongly indicates that nitrogen stimulates the growth of non-diamond carbon. More information about the different components of the Raman spectra can be obtained by combining the present Raman measurements with micro-Raman spectroscopy. Other spectroscopic techniques such as energy-resolved $\mathrm{CL}^{47,48}$ and photoluminescence ${ }^{44,45}$ can provide additional insight.

\section{DISCUSSION}

The central area morphology observed at nitrogen additions of $10 \mathrm{sccm}$ and higher can be understood from the deterioration-gradient (DG) model, ${ }^{49,50}$ the principles of which will be briefly outlined here. In the nucleation phase, nuclei are formed that are bounded by $\{111\}$ and $\{001\}$ facets and have a random orientation. With a large $S_{\mathrm{ac}}$ or in the presence of nitrogen, the $\{111\}$ facets deteriorate due to twin formation. The remaining and newly formed $\{001\}$ facets have a high density of dislocations pointing radially outward from the center of the nucleus, which induces a high step growth velocity on these facets. ${ }^{51,52}$ As a result, the nuclei develop into hemispherical structures that are bounded by $\{001\}$ facets with their normals perpendicular to the surface of the structure. A number of such structures can be seen in the SEM image in Fig. 7. Now, the vertical gradient of growth species, which exists in the flame, causes the $\{001\}$ facets that are oriented parallel to the substrate surface, the top facets, to grow faster than the ones with a different ori- 


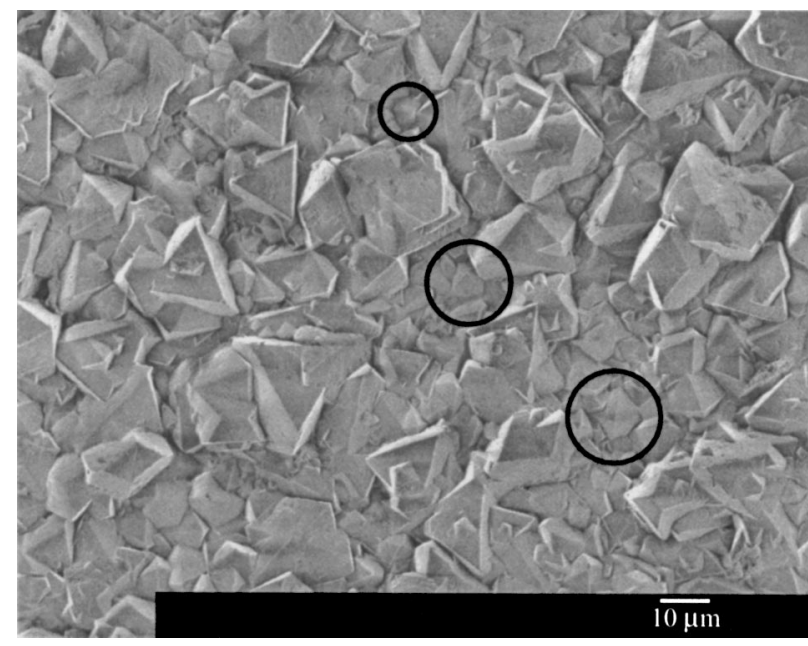

FIG. 8. SEM image of the central area morphology of the $5 \mathrm{sccm}$ sample grown with $d=2.2 \mathrm{~mm}$; the circles enclose some $\langle 001\rangle$ oriented crystallites without $\{001\}$ top facets.

entation, which are lying closer to the substrate. The difference in growth rate increases the height difference between the top facets and the other ones. The latter will be in contact with a less activated gas phase than the top facets, resulting in an inhibition of next layer growth by complete deterioration or disturbed growth due to insufficient growth species. It should be kept in mind that during diamond deposition both processes in the DG growth model, nucleation and further growth, take place simultaneously: $\{001\}$ facets parallel to the substrate surface grow, immediately after their nucleation, faster than $\{001\}$ facets directed otherwise. Main indications that the DG growth mechanism is active in a diamond CVD process are the presence of crystallites with differently sized $\{001\}$ top facets and/or the presence of deteriorated $\{111\}$ facets between the crystallites.

As described in Sec. III B, the crystallites of layers grown with nitrogen flows of $10 \mathrm{sccm}$ or higher have a $\langle 001\rangle$ direction nearly perpendicular to the substrate, but have no $\{001\}$ top facets. Figures $3(\mathrm{e})-3(\mathrm{~h})$ clearly show that the $\{111\}$ side facets are usually still smooth at newly formed areas, i.e., close to the top of the crystallites and at their mutual $\{111\}$ edges. However, at positions further from the top, which are longer exposed to the gas phase, the facets become more and more deteriorated by multiple twinning or other forms of secondary nucleation. For the persistence of the columnar crystallite structure it is essential to grow sufficiently fast and generate new $\{111\}$ areas before they can degenerate by twin formation. Therefore, growth of a $\langle 001\rangle$ oriented column depends critically on the density and activity of step nucleation centers like dislocations close to its top. By chance it is possible that twin formation takes place so close to the top of a crystallite that it obstructs the growth in the direction perpendicular to the substrate surface. As a result the crystallite falls back in the shadow of the remaining fast-growing columns and encounters a more and more depleted gas phase. This leads to an increasingly rapid further deterioration of the columnar structure into the amorphous or nanocrystalline ball-like features as can be observed for the smaller crystallites in Fig. 3.
High nitrogen concentrations obviously lead to gas phase conditions that allow fast growth for the crystallites that are able to generate new growth layers with sufficient speed. On the other hand, increasing nitrogen concentrations enlarge the chance of a growth rate obstruction by twin formation at the top of the crystallite, which results in a rapid fallback and deformation of the columnar structure into a ball-like one. The described mechanism explains why most deposits shown in Fig. 3 have a top layer with crystalline features and a bottom layer, which is highly deteriorated. Furthermore, it agrees well with the observation that with an increased nitrogen concentration the crystallite structures enlarge in size but decrease in density [Figs. 3(e)-3(h)], until finally virtually no crystallite grows fast enough to survive [Fig. 3(i)].

The central area of the $0 \mathrm{sccm}$ sample shows randomly oriented crystallites with both $\{111\}$ and $\{001\}$ facets. Obviously, there is neither a clear preference for bounding faces nor for orientation, which means that the randomly formed nuclei can grow to become crystallites, which keep the initial morphology and orientation. The growth under these conditions is free from the biasing influence of secondary nucleation by nitrogen addition. Nitrogen was added during the deposition of the $5 \mathrm{sccm}$ sample, which shows $\{111\}$ top facets and $\langle 111\rangle$ texturing. The simultaneous occurrence of $\{111\}$ topped crystallites and twins on top of the facets is noticeable. The alignment of $\{111\}$ facets more or less parallel to the substrate can be observed for values of the $\alpha$ parameter below 1.5, the $\alpha$ parameter being defined as $\sqrt{ } 3$ times the $\langle 001\rangle$ growth rate divided by the $\langle 111\rangle$ growth rate. ${ }^{53}$ According to Tamor and Everson ${ }^{54}$ on the role of twin formation in CVD diamond films, twin formation on $\{111\}$ facets occurs for values of the $\alpha$ parameter ${ }^{53}$ larger than 1.5. Therefore, the presence of both $\{111\}$ top faces and twins on them seems to be in conflict. Some light in this matter may come from the observation of the central morphology of a second sample, which was grown with a nitrogen addition of $5 \mathrm{sccm}$ under nearly the same experimental conditions, the value of $d$ being $2.2 \mathrm{~mm}$ instead of $2.0 \mathrm{~mm}$. Part of this sample's central area is shown in Fig. 8. The central areas of the two $5 \mathrm{sccm}$ samples are quite similar, although the one in Fig. 8 shows somewhat more twin formation. Close examination of the morphology of this sample shows small $\langle 001\rangle$ textured crystallites without $\{001\}$ top facets (encircled), that can also be observed in the central area of the $10 \mathrm{sccm}$ sample [Fig. 3(c)]. For this type of crystallite the $\alpha$ parameter is 3 or more. No $\langle 001\rangle$ oriented crystallites with $\{001\}$ top facets, which have an $\alpha$ value of 2.5, are observed in Fig. 8 , which indicates that the change of the $\alpha$ parameter from 1.5 to 3 occurs within a very narrow parameter window. This means that a small change of the growth conditions can already result in a large change of the $\alpha$ parameter, leading to huge morphological changes. It is known that during a growth run of $1 \mathrm{~h}$ the value of $S_{\text {ac }}$ decreases by some promilles. This decrease of $S_{\text {ac }}$ means an increase of the nitrogen fraction in the feed gases, which should lead to an increase of the $\alpha$ parameter. Supposing that the growth conditions at the beginning of the growth run of the $5 \mathrm{sccm}$ sample of Fig. 3(b) resulted in crystallites with an $\alpha$ parameter just below 
1.5 , which gives $\{111\}$ facets with a relatively small inclination to the substrate, a slight decrease of $S_{\mathrm{ac}}$ during the run can be the cause of an increase of the $\alpha$ parameter to a value larger than 1.5 , which enables twin formation on the already grown $\{111\}$ facets.

As mentioned already, the absence of $\{001\}$ topped $\langle 001\rangle$ oriented crystallites in Fig. 8 demonstrates how narrow the process window is, within which, under the present experimental conditions, all major changes in morphology that can be observed in Fig. 3 occur. The chance of having conditions that give a central morphology consisting of $\{001\}$ topped $\langle 001\rangle$ oriented crystallites ( $\alpha$ parameter 2.5), appears to be very small and may even be zero. More detailed research of the parameter space around a nitrogen addition of $5 \mathrm{sccm}$ will show, whether the possibility exists of growing a $\{001\}$ topped $\langle 001\rangle$ textured morphology under the present experimental conditions, and can unveil the formation mechanism of the central morphology observed for the $5 \mathrm{sccm}$ samples. Useful experiments in this respect may be the addition of a range of nitrogen flows closely around $5 \mathrm{sccm}$ to "scan" the narrow range of nitrogen flows in which the large change of the $\alpha$ parameter takes place, the variation of $S_{\text {ac }}$ at a fixed nitrogen addition, and the application of different deposition times to monitor the development of the morphology in time.

The radial variation of the morphology of the $0 \mathrm{sccm}$ sample must result from differences in the composition and activation level of the local gas phase. One thing that changes radially in the gas phase is the concentration of nitrogen-containing radicals. Numerical simulations ${ }^{17-19}$ show that nitrogen from the ambient does not come closer than $1.3 \mathrm{~mm}$ away from the flame axis, even if $d$ is as large as $2.6 \mathrm{~mm}$. In correspondence with this, the CN LIF profile measured during the growth run without nitrogen addition shows no or hardly any CN LIF signal in a central area with a radius of at least $1.5 \mathrm{~mm}$ (Fig. 1). From this (almost) zero signal it can be concluded that there is no $\mathrm{CN}$ present in the central area, or that all LIF signals coming from $\mathrm{CN}$ are quenched. The validity of the first option is confirmed by the CRDS measurements mentioned above, ${ }^{28}$ which show that there is virtually no CN in the central area. In Sec. III A it has already been argued from the similarity between the results of LIF and CRDS measurements, that the LIF profiles in Fig. 1 give a good representation of the $\mathrm{CN}$ density. Because of the linear relation between the CN LIF signal in the central area and the added nitrogen flow reported in earlier work, ${ }^{15}$ $\mathrm{CN}$ can be used as an indicator for the conversion of nitrogen to nitrogen-containing species, with the statement that not all nitrogen chemistry involves $\mathrm{CN}$. Observing the $0 \mathrm{sccm}$ profile it can be seen that, starting at a certain radial distance, the $\mathrm{CN}$ signal begins to rise and increases with increasing radial distance until a maximum value, meaning that with increasing radial distance more nitrogen is converted. This radial increase of nitrogen conversion can be considered as a range of increasing nitrogen additions starting from zero in the central area. From this, the central area morphologies that are observed for increasing nitrogen additions are expected to be found on the $0 \mathrm{sccm}$ sample when going radially outward. As can be seen in Fig. 4, this expectation is met. Vice versa, the $\{001\}$ topped crystals first encountered at a radial distance of
$3.2 \mathrm{~mm}$ [Fig. 4(c)], at which the CN LIF signal still increases, should be observed in the central area at an appropriate nitrogen addition. From Fig. 3, however, it follows that, except for a very occasional one, crystallites topped with $\{001\}$ facets are not found in the central area for any nitrogen addition. The fact that such crystallites are observed in the annulus of the $0 \mathrm{sccm}$ sample [Figs. 4(c)-4(e)], means that besides the radial variation of the concentration of nitrogen-containing species, there must be another factor that is important in determining the crystallite morphologies that are encountered at different radii. This factor may be a radial variation of gas composition other than that related to nitrogen. Such a variation is caused by differences in radial density distributions of several species, some of which follow from LIF measurements by Klein-Douwel and ter Meulen, ${ }^{14}$ which were performed during diamond growth with $S_{\mathrm{ac}}$ $=5 \%$ and various $d$ values. At $d$ values comparable to ours and a radial distance of about $3.2 \mathrm{~mm}$, where the first $\{001\}$ faces in our $0 \mathrm{sccm}$ sample are observed, the LIF signal of atomic hydrogen at $0.10 \mathrm{~mm}$ above the substrate is similar to that in the center, suggesting equal concentrations, whereas the $C_{2}$ signal at the same height has decreased considerably.

Oxygen from the ambient air is likely to be important in determining the radial variation of species profiles. Its presence at the radial position of the $\{001\}$ topped crystallites is expected from the fact that nitrogen from the surrounding air is found. It lowers the local carbon supersaturation and interacts with the flame, thus influencing its composition and contributing to the conditions that lead to the observed $\{001\}$ topped crystallites [Figs. 4(c)-4(e)]. The influence of the local flame composition on the radial morphology of flamegrown diamond samples and the importance of oxygen from the surrounding air in determining the local flame composition have been discussed by García and Vázquez, ${ }^{55}$ who studied the morphology of flame-grown samples as a function of (overall) flame composition, substrate temperature, and radial position. The different sizes of the $\{001\}$ facets are indicative of growth via the DG model. The fact that these facets are observed means, that at the local conditions the growth in the $\langle 001\rangle$ direction is slowed down with respect to that in the $\langle 111\rangle$ direction. Since nitrogen enhances the $\langle 001\rangle$ growth rate, there must be one or more factors that more than compensate for its influence. A lower local carbon supersaturation may very well be such a factor. If indiffused or entrained oxygen from the surrounding air is in part responsible for the formation of the $\{001\}$ topped crystallites, it may be possible to grow such a morphology in the central area at the present value of $d$, by adding nitrogen and lowering $S_{\text {ac }}$.

The morphology found outside the $\langle 001\rangle$ textured ring of the $0 \mathrm{sccm}$ sample [Fig. 4(f)] is, apart from its smaller crystallites' dimensions, very similar to that of the central area of the $5 \mathrm{sccm}$ sample. Since the morphology is found at a radial position of $4.1 \mathrm{~mm}$ outside the center, the local carbon supersaturation is expected to be lower. This means that this morphology is also expected to occur in the central area when $S_{\text {ac }}$ values lower than $4 \%$ are applied, which is an interesting finding for its further exploration.

A study of the central morphology similar to the one described in this article in nearly the same set-up has been 
conducted by Schermer and De Theije. ${ }^{5}$ Using a $d$ value of $1.2 \mathrm{~mm}$, they observed $\langle 001\rangle$ texturing and $\{001\}$ morphology for a certain range of nitrogen flows. Within this range the number of $\{001\}$ topped crystallites decreased and the deterioration of their side facets increased with an increasing nitrogen flow. At a certain addition, top facets have (almost) fully disappeared and only largely deteriorated columnar structures are left. This evolution of the morphology shows similarity with our observations. The conditions applied by Schermer and De Theije are such that $\{001\}$ top facets do not grow out of the crystals, as in our experiments. In contrast to the present results no $\langle 111\rangle$ texturing and $\{111\}$ topped crystallites are found in the central area of their diamond deposits. This deviation must be due to the difference in $d$ values, demonstrating the large influence of $d$ on the properties of the deposited diamond layers. The influence of $d$ may be related to its effect on concentrations of flame species close to the substrate. The concentration of some species, mainly the radicals formed at the primary flame front, will decrease as the distance from the flame front increases, as shown for the $\mathrm{CH}$ radical by numerical simulations of oxyacetylene diamond CVD performed by Okkerse et al. ${ }^{35}$ Concentrations of other species, in particular more stable ones such as CO, will increase. Because the concentrations of different flame species have a different dependence on $d$, the gas phase composition close to the substrate and, consequently, the properties of the deposited diamond layers change with $d$. More investigations of both experimental and theoretical nature are required to get a clearer and more quantitative insight into this matter.

In Sec. III C, the behavior of the central area growth rate for samples grown with a nitrogen addition of $5 \mathrm{sccm}$ and more, has been (partly) ascribed to variations in $d$. Together with the contents of the previous paragraph, this may suggest that the changes in morphology may also result from the variations in $d$ for the different samples. A comparison of Fig. 3 and Table I shows, however, that this is highly unlikely. The clearly progressing secondary nucleation of the $\{111\}$ facets with increasing nitrogen addition for the samples grown with $10-100 \mathrm{sccm}$ of nitrogen, e.g., does not go together with a continuous increase or decrease of $d$. Obviously, the variation of $d$ within the present set of samples is large enough to influence the growth rate, but too small to significantly influence the morphology.

From a comparison of the Raman spectra in Fig. 6(d) and the SEM images of the central area of the samples, there appears to be a relation between the two. As mentioned in the description of the results, the width of the broad-band on the high wave number side of the spectrum decreases stepwise at nitrogen flows of 10, 25, and $60 \mathrm{sccm}$. This stepwise narrowing coincides with the morphological and structural transitions between 5 and $10 \mathrm{sccm}$, and between 15 and 25 $\mathrm{sccm}$. Obviously, the transition from the $\{111\}$ topped to nontopped $\langle 001\rangle$ textured crystallites and the breaking up of the layer go together with changes in the layer composition, which lead to a weaker $\mathrm{G}$ band and a stronger $\mathrm{D}$ band. The narrowing of the broad-band at $60 \mathrm{sccm}$, which is the smallest of the changes in width, is not accompanied by a clear morphological change in the layer. The origin of the correla- tion between the layer morphology and the changes in the Raman signal does not become clear from the present measurements. In this respect, micro-Raman spectroscopy can provide valuable additional information.

Since the central CN LIF signal increases (linearly) with the added nitrogen flow, ${ }^{15}$ changes of the diamond properties observed upon nitrogen addition may very well be directly related to the presence of the $\mathrm{CN}$ radical. However, as argued in previous work ${ }^{14,15}$ correlations between the CN LIF signal, the deposition chemistry, and the properties of the deposited diamond layer do not necessarily mean, that $\mathrm{CN}$ itself is responsible for the observed changes upon nitrogen addition. Because of the relatively large height of $100 \mu \mathrm{m}$ above the substrate at which the LIF signal is measured, it is possible that on its way to the substrate $\mathrm{CN}$ is transformed into a closely related species by reactive collisions with other flame species. Nevertheless, the CN LIF signal can be used to monitor the deposition process and, in this way, control the properties of the deposited layers. To do so, the relation between the $\mathrm{CN}$ signal and the properties of the layer must be established for the used reactor and the $\mathrm{CN}$ intensity should be calibrated.

An indication that $\mathrm{CN}$ itself is active at the surface comes from the observation that the twin formation increases with the nitrogen flow. In Sec. I, a model of Butler ${ }^{29}$ was mentioned, which explains the increased twin formation observed upon nitrogen addition via a mechanism involving surface-bound CN. Since it follows from the discussion of the morphology in terms of the DG model that twinning is one of the central processes that determine the crystallite morphology ${ }^{54}$ and the growth rate, the model of Butler links the gas-phase $\mathrm{CN}$ to the properties of the diamond layers. This link strongly supports the idea that $\mathrm{CN}$ is very important in determining the effects of nitrogen addition on CVD diamond growth. Conclusive evidence in this respect should be obtained from further investigations. Species distributions may be measured even closer to the substrate and measurements on species other than $\mathrm{CN}$ could be conducted. An important candidate for such measurements is the HCN molecule, which is mentioned in relation with nitrogen addition to diamond CVD processes, ${ }^{8,26}$ and is expected to be present in larger concentrations in the flame than $\mathrm{CN}^{8,18,19}$ Furthermore, $\mathrm{NCO}$ is interesting, because it contains one atom from each of the three gases that form the combustion mixture. From Refs. 17-19 it follows that it may be useful to pay attention to the $\mathrm{N}, \mathrm{NH}, \mathrm{NH}_{2}$, and $\mathrm{NH}_{3}$ radicals as well. Despite all the information that can be obtained from gas phase measurements, the ultimate source of information would be measurements of species and processes at the surface, e.g., by "freezing" the deposition process at a certain moment and measuring the surface composition and structure, or by using in situ surface-sensitive techniques. Besides experimental work, modeling studies can yield a significant contribution to a better insight into the surface mechanisms that take place, and help to identify the species that play a role. 


\section{CONCLUSIONS}

Nitrogen addition during flame deposition of diamond was studied using LIF for in situ measurements of CN distributions in the flame and a number of ex situ techniques for the detailed characterization of the grown layers. From the LIF measurements it was found that added nitrogen has the largest influence in the area around the flame axis, whereas nitrogen from the ambient air is the dominant nitrogen source in an area of the flame that lies more outward. Between these two areas, both nitrogen sources are of importance. The collisional quenching and LIF detection efficiency in a central area with a radius of at least $1.5 \mathrm{~mm}$ were found to be constant. The DG model for diamond growth has proven to be very useful for understanding most of the morphologies encountered in the diamond deposits. A very fast change of the $\alpha$ parameter from below 1.5 to a value of 3 or more was observed to be caused by local fluctuations in the growth conditions. This indicates that for the substrate-toflame-front distance and acetylene supersaturation applied in the present work the growth of $\{001\}$ topped $\langle 001\rangle$ textured layers may be impossible. The radially changing morphology observed in the sample grown without nitrogen addition is caused by variations in the local gas composition, which result from the interaction of the flame with nitrogen and oxygen from the ambient air, and from differences in radial concentration profiles of the flame species. Oxygen is likely to be an important factor in causing the latter differences. The central area growth rate found for the used experimental conditions increases upon the addition of nitrogen. Between 5 and $25 \mathrm{sccm}$ of nitrogen, this increase in growth rate does not seem to depend much on the added amount of nitrogen. The diamond quality decreases upon nitrogen addition, which is probably caused by a stimulating effect of nitrogen on the growth of non-diamond carbon material. A correlation, the origin of which is not clear, was observed between morphological changes in the layers and changes in the Raman signal of non-diamond carbon compounds. From the discussion of the measurements it follows that $\mathrm{CN}$ is likely to be responsible for the effects of nitrogen addition on CVD diamond growth.

\section{ACKNOWLEDGMENTS}

Dr. J. van Bentum is kindly acknowledged for recording the Raman spectra. L. Gerritsen is gratefully acknowledged for his technical assistance in maintaining the deposition setup. H. Geurts is acknowledged for his help with the scanning electron microscope.

${ }^{1}$ S. Jin and T. D. Moustakas, Appl. Phys. Lett. 65, 403 (1994).

${ }^{2}$ R. Locher, C. Wild, N. Herres, D. Behr, and P. Koidl, Appl. Phys. Lett. 65, 34 (1994).

${ }^{3}$ G. Z. Cao, J. J. Schermer, W. J. P. van Enckevort, W. A. L. M. Elst, and L. J. Giling, J. Appl. Phys. 79, 1357 (1996).

${ }^{4}$ J. Asmussen, J. Mossbrucker, S. Khatami, W. S. Huang, B. Wright, and V. Ayres, Diamond Relat. Mater. 8, 220 (1999).

${ }^{5}$ J. J. Schermer and F. K. de Theije, Diamond Relat. Mater. 8, 2127 (1999).

${ }^{6}$ S. Bohr, R. Haubner, and B. Lux, Appl. Phys. Lett. 68, 1075 (1996)

${ }^{7}$ W. Müller-Sebert, E. Wörner, F. Fuchs, C. Wild, and P. Koidl, Appl. Phys. Lett. 68, 759 (1996)
${ }^{8}$ B. Atakan, M. Beuger, and K. Kohse-Höinghaus, Phys. Chem. Chem. Phys. 1, 705 (1999).

${ }^{9}$ G. Z. Cao, L. J. Giling, and P. F. A. Alkemade, Diamond Relat. Mater. 4, 775 (1995).

${ }^{10}$ J. A. Freitas, J. E. Butler, and U. Strom, J. Mater. Res. 5, 2502 (1990).

${ }^{11}$ A. T. Collins, Diamond Relat. Mater. 1, 457 (1992).

${ }^{12}$ A. Bergmaier, G. Dollinger, T. Faestermann, C. M. Frey, M. Ferguson, H. Güttler, G. Schulz, and H. Willerscheid, Diamond Relat. Mater. 5, 995 (1996).

${ }^{13}$ J. J. Schermer, W. A. L. M. Elst, and L. J. Giling, Diamond Relat. Mater. 4, 1113 (1995).

${ }^{14}$ R. J. H. Klein-Douwel, J. J. Schermer, and J. J. ter Meulen, Diamond Relat. Mater. 7, 1118 (1998).

${ }^{15}$ R. L. Stolk, M. M. J. W. van Herpen, J. J. ter Meulen, and J. J. Schermer, J. Appl. Phys. 88, 3708 (2000).

${ }^{16}$ D. B. Oakes, J. E. Butler, K. A. Snail, W. A. Carrington, and L. M. Hanssen, J. Appl. Phys. 69, 2602 (1991).

${ }^{17}$ M. Okkerse, M. H. J. M. de Croon, C. R. Kleijn, H. E. A. van den Akker, and G. B. Marin, Electrochem. Soc. Proc. 2000-13, 317 (2000).

${ }^{18}$ R. Okkerse-Ruitenberg, Ph.D. thesis, Delft University of Technology, 2000

${ }^{19}$ M. Okkerse, M. H. J. M. de Croon, C. R. Kleijn, G. B. Marin, and H. E. A. van den Akker, J. Appl. Phys. 92, 4095 (2002).

${ }^{20}$ T. Vandevelde, M. Nesladek, C. Quaeyhaegens, and L. Stals, Thin Solid Films 308-309, 154 (1997).

${ }^{21}$ M. D. Welter and K. L. Menningen, J. Appl. Phys. 82, 1900 (1997).

${ }^{22}$ S. J. Firchow and K. L. Menningen, J. Phys. D 32, 937 (1999).

${ }^{23}$ J. A. Smith, K. N. Rosser, H. Yagi, M. I. Wallace, P. W. May, and M. N. R. Ashfold, Diamond Relat. Mater. 10, 370 (2001).

${ }^{24}$ R. L. Stolk, M. M. J. W. van Herpen, J. J. Schermer, and J. J. ter Meulen, Proc. Combust. Inst. 28, 1447 (2000)

${ }^{25}$ R. S. Tsang, C. A. Rego, P. W. May, M. N. R. Ashfold, and K. N. Rosser, Diamond Relat. Mater. 6, 247 (1997).

${ }^{26}$ S. M. Leeds, P. W. May, M. N. R. Ashfold, and K. N. Rosser, Diamond Relat. Mater. 8, 226 (1999).

${ }^{27}$ T.-M. Hong, S.-H. Chen, Y.-S. Chiou, and C.-F. Chen, Appl. Phys. Lett. 67, 2149 (1995).

${ }^{28}$ R. L. Stolk and J. J. ter Meulen, J. Chem. Phys. 117, 8281 (2002).

${ }^{29}$ J. E. Butler, Presented at the Sixth International Conference on New Diamond Science and Technology, Pretoria, South Africa, 31 August-4 September 1998

${ }^{30}$ J. Luque and D. R. Crosley, J. Chem. Phys. 104, 2146 (1996).

${ }^{31}$ D. I. Shin, G. Peiter, T. Dreier, H.-R. Volpp, and J. Wolfrum, Proc. Combust. Inst. 28, 319 (2000).

${ }^{32}$ J. J. Schermer, J. E. M. Hogenkamp, G. C. J. Otter, G. Janssen, W. J. P. van Enckevort, and L. J. Giling, Diamond Relat. Mater. 2, 1149 (1993).

${ }^{33}$ R. J. H. Klein-Douwel, J. J. L. Spaanjaars, and J. J. ter Meulen, J. Appl. Phys. 78, 2086 (1995).

${ }^{34}$ A. Hirano and M. Tsujishita, Appl. Opt. 33, 7777 (1994).

${ }^{35}$ M. Okkerse, C. R. Kleijn, M. H. J. M. de Croon, H. E. A. van den Akker, and G. B. Marin, J. Appl. Phys. 88, 4417 (2000).

${ }^{36}$ P. K. Bachmann and D. U. Wiechert, Diamond Relat. Mater. 1, 422 (1992).

${ }^{37}$ D. S. Knight and W. B. White, J. Mater. Res. 4, 385 (1989).

${ }^{38}$ W. A. Yarbrough and R. Roy, Mater. Res. Soc. Symp. Proc. EA-15, 33 (1988).

${ }^{39}$ N. Wada, P. J. Gaczi, and S. A. Solin, J. Non-Cryst. Solids 35/36, 543 (1980)

${ }^{40}$ M. Ramsteiner, J. Wagner, Ch. Wild, and P. Koidl, J. Appl. Phys. 62, 729 (1987).

${ }^{41}$ A. Grill, Diamond Relat. Mater. 8, 428 (1999).

${ }^{42}$ M. Ramsteiner and J. Wagner, Appl. Phys. Lett. 51, 1355 (1987).

${ }^{43}$ G. Adamopoulos, K. W. R. Gilkes, J. Robertson, N. M. J. Conway, B. Y. Kleinsorge, A. Buckley, and D. N. Batchelder, Diamond Relat. Mater. 8, 541 (1999).

${ }^{44}$ L. Bergman, B. R. Stoner, K. F. Turner, J. T. Glass, and R. J. Nemanich, J. Appl. Phys. 73, 3951 (1993).

${ }^{45}$ L. Bergman, M. T. McClure, J. T. Glass, and R. J. Nemanich, J. Appl. Phys. 76, 3020 (1994)

${ }^{46}$ S. A. Grot, C. W. Hatfield, G. Sh. Gildenblat, A. R. Badzian, and T. Badzian, Mater. Res. Soc. Symp. Proc. p. 633 (1990).

${ }^{47}$ L. Pereira, E. Pereira, A. Cremades, and J. Piqueras, Diamond Relat. Mater. 5, 1189 (1996)

${ }^{48}$ R. L. Stolk, J. G. Buijnsters, J. J. Schermer, J. J. ter Meulen, N. Teofilov, 
R. Sauer, M. J. Fransen, J. H. A. Vasterink, and J. te Nijenhuis, Diamond Relat. Mater. (submitted).

${ }^{49}$ F. K. de Theije, Ph.D. thesis, University of Nijmegen, 2001.

${ }^{50}$ J. J. Schermer, F. K. de Theije, and W. A. L. M. Elst, J. Cryst. Growth 243, 302 (2002).

${ }^{51}$ W. J. P. van Enckevort, G. Janssen, J. J. Schermer, and L. J. Giling, Diamond Relat. Mater. 4, 250 (1995).
${ }^{52}$ J. J. Schermer, F. K. de Theije, and L. J. Giling, J. Cryst. Growth 165, 387 (1996).

${ }^{53}$ C. Wild, P. Koidl, W. Müller-Sebert, H. Walcher, R. Kohl, N. Herres, R. Locher, R. Samlenski, and R. Brenn, Diamond Relat. Mater. 2, 158 (1993).

${ }^{54}$ M. A. Tamor and M. P. Everson, J. Mater. Res. 9, 1839 (1994).

${ }^{55}$ I. García and A. J. Vázquez, Thin Solid Films 325, 99 (1998). 